\title{
Pseudo class III treatment in 2-year-old children
}

\author{
Maen Mahfouz \\ Department of Orthodontics and Pediatric Dentistry, Arab American University, Jenin, Palestine \\ Email: mnmahfouz2005@yahoo.com
}

Received 26 November 2013; revised 27 December 2013; accepted 9 January 2014

Copyright (C) 2014 Maen Mahfouz. This is an open access article distributed under the Creative Commons Attribution License, which permits unrestricted use, distribution, and reproduction in any medium, provided the original work is properly cited. In accordance of the Creative Commons Attribution License all Copyrights (C) 2014 are reserved for SCIRP and the owner of the intellectual property Maen Mahfouz. All Copyright (C) 2014 are guarded by law and by SCIRP as a guardian.

\section{ABSTRACT}

Timing of orthodontic treatment especially for children with developing Class III malocclusions has always been somewhat controversial. Pseudo class III malocclusion is recommended to be treated early as this type of malocclusion doesn't diminish with age. Untreated pseudo class III may lead to serious problems. The case report describes pseudo class III in primary dentition successfully treated by using Protrusive Arch Wire.

\section{KEYWORDS}

\section{Pseudo Class III; Treatment; Children}

\section{INTRODUCTION}

Timing of orthodontic treatment [1], especially for children with developing class III malocclusions, has always been somewhat controversial.

The earlier the interceptive phase is initiated, the greater the orthopedic effects will be to the detriment of the unavoidable orthodontic and orthopedic effects [2]. Esthetics for the child implies the improved self-esteem considering the psychological factor [3].

The diagnosis of pseudo class III malocclusion differs from that of skeletal class III malocclusion because it is defined as functional forward displacement of the mandible as a result of retroclined maxillary incisors [4].

The aim of early treatment of this type of malocclusion is to correct pseudo class III, otherwise it can lead to serious class III mallocclusion which would be possible to treat only with combined orthodontic and orthognatic method [5].

\section{THE CASE}

A 2-year-old boy with his father attended to my orthodontic clinic with chief compliant of anterior crossbite.
He was in primary dentition. The general health of patient was good.

Records: records like OPG and Cephalometric radiograph were taken for diagnosis.

Extraoral examination: mesomorphic built, normal gait and posture. Face was mesocephalic with competent lips. Profile was straight (Figures 1-3).

Intraoral examination: Soft tissues normal.

\begin{tabular}{|c|c|c|}
\hline & E D C B A & A B C D E \\
\hline & $\mathrm{E} \mathrm{DCBA}$ & A B C D E \\
\hline
\end{tabular}

Maxillary arch: symmetrical with upper primary central incisors retroclined.

Mandibular arch: symmetrical, completely overlapping the maxillary anterior teeth 211.

Intra occlusal examination (Figures 4-6).

1) Mesial step molar relationship;

2) Reverse overjet;

3) Functional shift of the mandible to right side on closure.

Radiographic examination by panoramic view has revealed that all permanent unerupted teeth present except third molars, while cephalometric radiograph showed no adenoid enlargement (Figures 7 and 8).

\subsection{Diagnosis}

The clinical examination revealed pseudo class III on account of an anterior crossbite in the presence of forward mandibular displacement and functional shift due to premature contact on upper right $\mathrm{B}$. SO the starting point in diagnosis was by establishing centric relation through guiding the mandible into centric relation.

Treatment Objectives: forward movement of AA maxillary incisors, eliminating functional shift, mandibular displacement and premature contact.

Treatment plan: fixed orthodontic treatment by using Protrusive Arch Wire for forward movement of AA. 


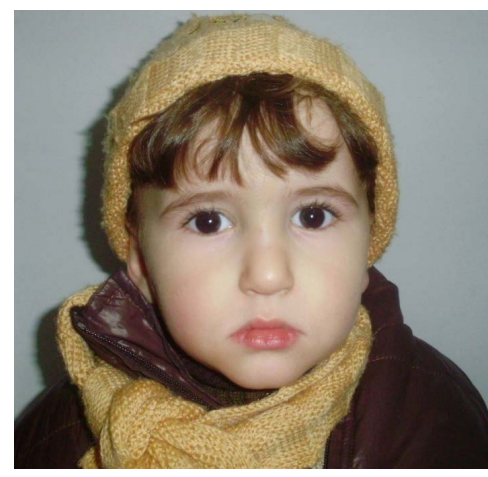

Figure 1. Frontal extraoral view.

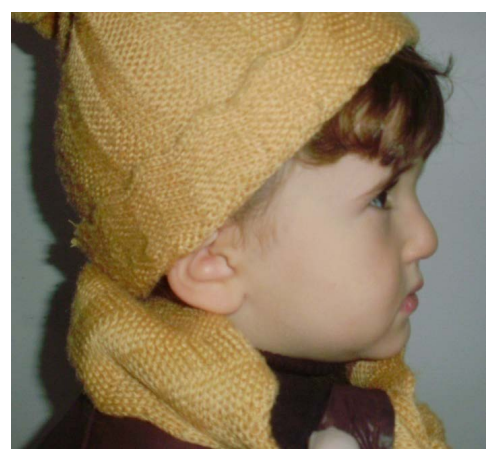

Figure 2. Profile view.

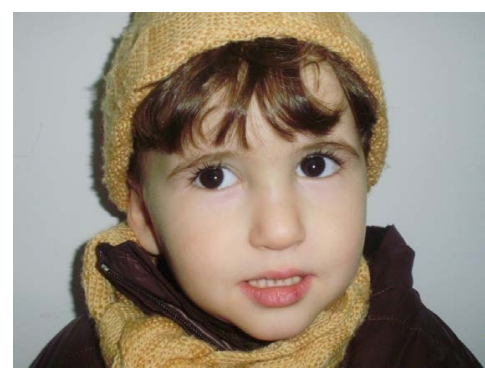

Figure 3. Smile view.

\subsection{Treatment Procedure}

Behavior management for this child has been carried out by direct modeling through his cousin 6 years old who has been treated in my orthodontic clinic, after he became familiar with dental office, treatment started so a bondable tubes placed on the buccal surfaces of upper E's on both sides with brackets (slot 22) placed on the labial surface of the upper A's. Then placement of upper Niti arch wire rectangular $(16 \times 22)$ (Protrusive Arch Wire) was customized to the arch form of the patient. Gable bend made mesial to the bondable tubes on E's. arch wire exposed part coated with sleeve to prevent irritation to cheek (Figures 9-11).

After two weeks, I have done selective adjustment of the premature contact on the upper right $\mathrm{B}$ from the incisal edge so the patient could bite comfortably (Figures 12 and 13).

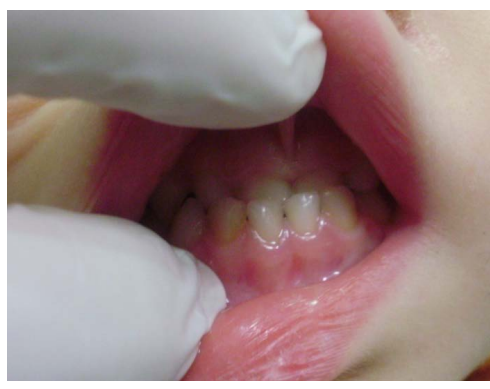

Figure 4. Intraoral frontal view.

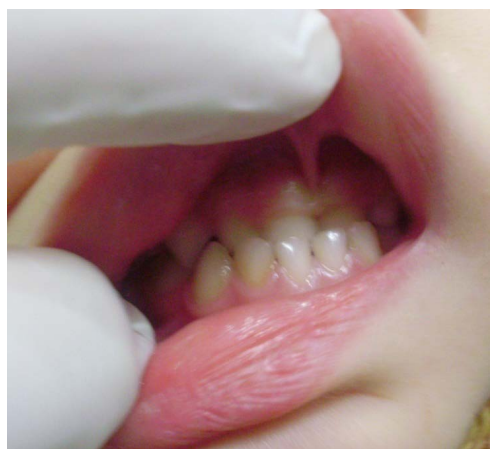

Figure 5. Right side intraoral.

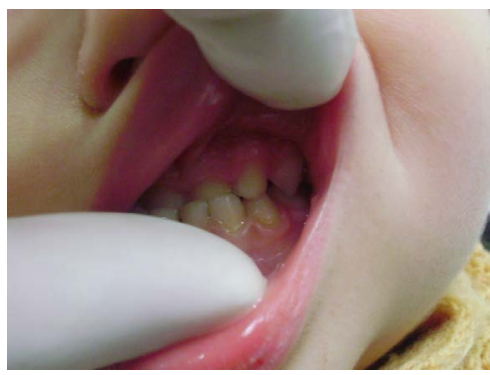

Figure 6. Left side intraoral.

The parents of the child were asked to apply oral hygiene measures like tooth cleaning, avoiding any habit or eating can damage the appliance and how to care with orthodontic appliance. The total treatment time was three weeks and appliance was removed on the end of the third week (Figure 14).

\section{DISCUSSION}

There is relatively little literature data about the treatment methods of Pseudo class III in primary dentition.

In the presented case new treatment modality is demonstrated which is quite simple and rapid method for treatment of Pseudo class III in primary dentition. Protrusive Arch Wire technique is a bypass fixed appliance technique needs less compliance in comparison to the removable appliance regarding wearing especially when dealing with child of 2 years old.

Protrusive arch wire as treatment modality is similar to $2 \times 2$ fixed appliance and $2 \times 4$ fixed appliance [3] from 


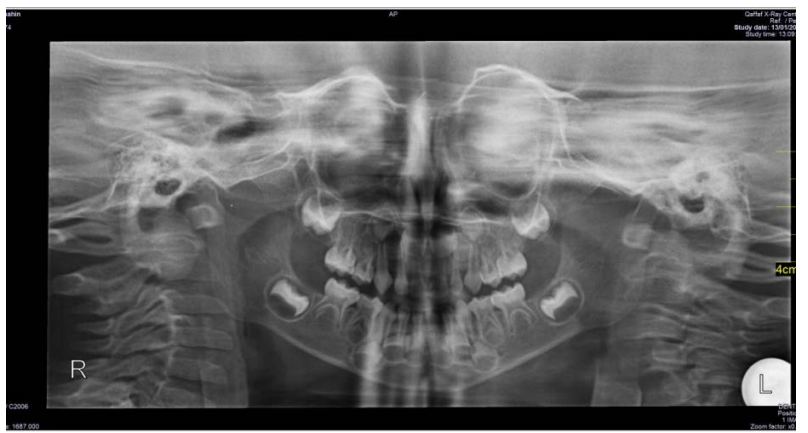

Figure 7. OPG (orthopantogram).

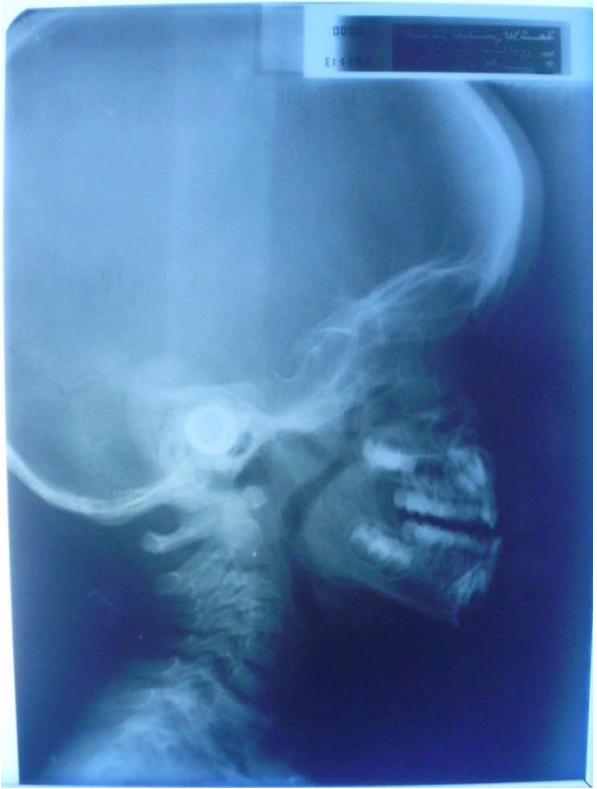

Figure 8. Lateral cephalometric radiograph.

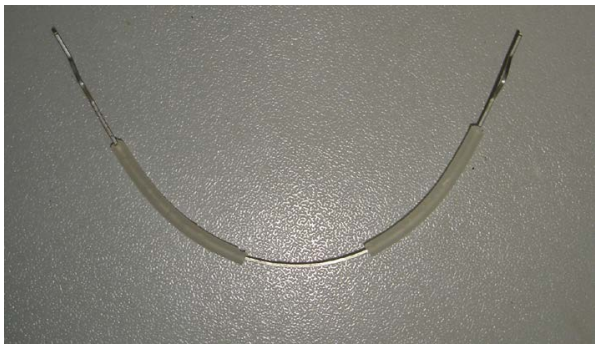

Figure 9. Upper view of protrusive arch wire.

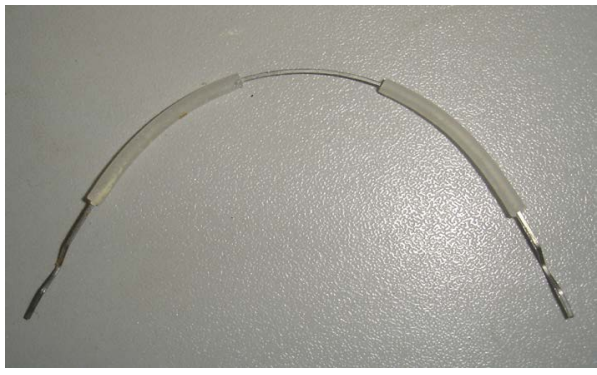

Figure 10. Lower view of protrusive arch wire.

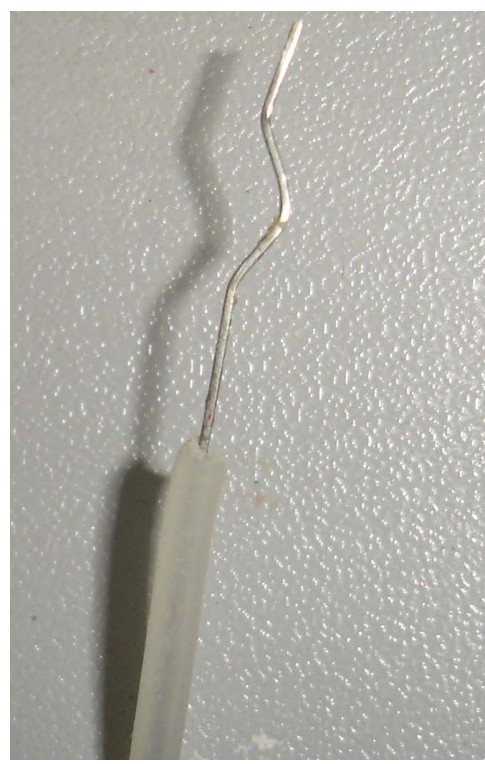

Figure 11. Gable bend.

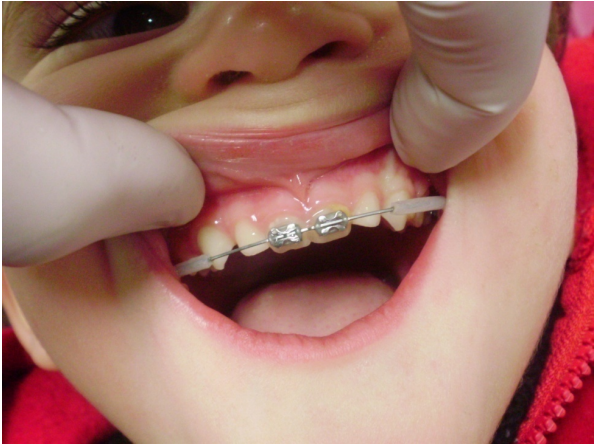

Figure 12. Mid-treatment (2 weeks).

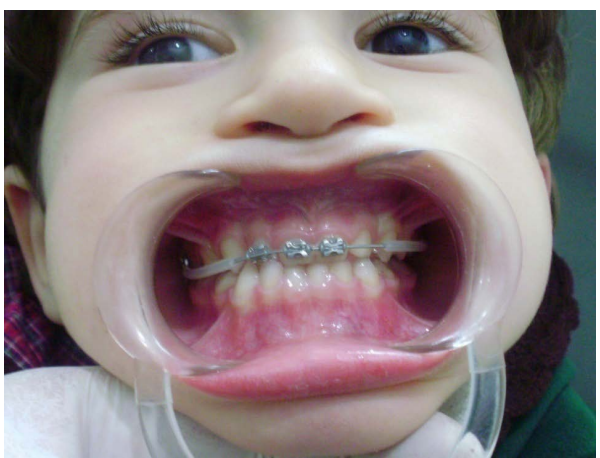

Figure 13. Mid-treatment (2 weeks).

one aspect it is as bypass arch wire but from another aspect it is different as it is $16 \times 22$ Niti arch wire in bracket slot 22 with $\mathrm{v}$ bend mesial to bondable buccal tubes and functions to procline upper anterior teeth while $2 \times 2$ or $2 \times 4$ is $16 \times 16$ chromuim cobalt in bracket slot 18 without mesial bends and functions to intrude upper anterior teeth.

Regarding the timing of orthodontic treatment, Some 


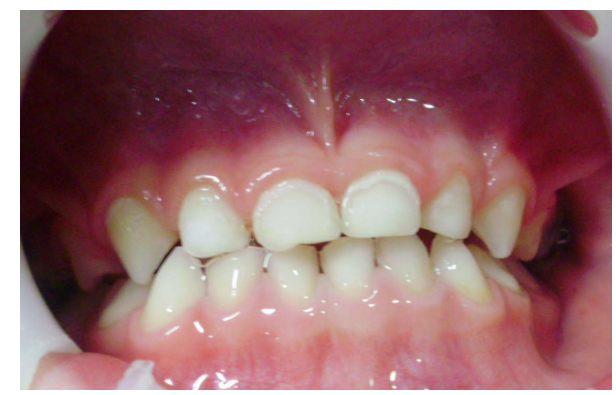

Figure 14. Post-treatment (3 weeks finished).

clinicians believed that in many patients, it was best to allow the eruption of the permanent teeth before initiating orthodontic treatment. However, delaying the treatment until the permanent dentition may cause loss of space required for the eruption of the canines [4]. This lack of space could be caused by the retroclination of upper incisors frequently found in pseudo Class III malocclusions. Therefore, a growing number of clinicians believe in the advantages of early intervention. Accordingly in the presented case orthodontic treatment was started in primary dentition as this type of malocclusion exacerbates during growth although many practitioners however still avoid early correction of pseudo-Class III in the deciduous dentition because of unfavourable experiences with the behavior of young patients. in spite of that the advantage to start treatment in primary dentition is enhancing positive attitude towards dental treatment in general, improving the esthetic and functional requirements for development and growth and considering the psychological factor of the parents especially if they aware about their child malocclusion.

\section{CONCLUSIONS}

1) Pediatric dentist is the pioneer in diagnosis and treatment of these cases as he/she is the primary care provider.
2) TSD and modeling are efficient methods in behavior management.

3) Periodic examination of primary occlusal relationship allows early correction of psuedo class III malocclusion.

4) This method of pseudo class III correction in the primary with a simple fixed (protrusive arch wire) appliance resulted in a positive overjet proclination of upper incisors contributes to the correction of anterior crossbite and the elimination of mandibular displacement.

\section{ACKNOWLEDGEMENTS}

This research was supported by the grants from Shanghai Commission for Science and Technology (KSCX2-YW-R-112), and Shanghai Leading Academic Discipline Project (J50101).

\section{REFERENCES}

[1] Campbell, P.H. (1983) The dilemma of class III treatment early or late? Angle Orthodontist, 53, 175-191.

[2] Kapust, A.J., Sinclair, P.M. and Turley, P.K. (1998) Cephalometric effects of face mask/expansion therapy in class III children. American Journal of Orthodontics \& Dentofacial Orthopedics, 113, 204-212. http://dx.doi.org/10.1016/S0889-5406(98)70141-6

[3] Proffit, W.R. (2000) Contemporary orthodontics. 3rd Edition, Mosby, St Louis, 276-277.

[4] Sharma, P.S. and Brown, R.V. (1968) Pseudo mesiocclusion: Diagnosis and treatment. Journal of Dentistry for Children, 35, 385-392.

[5] Estreia, F., Almerich, J. and Gascon, F. (1991) Interceptive correction of anterior crossbite. Journal of Clinical Pediatric Dentistry, 15, 157-159. 